\title{
THE IMPACT OF FX CENTRAL BANK INTERVENTION IN A NOISE TRADING FRAMEWORK
}

\author{
MiCHEL BEINE \\ PAUL DE GRAUWE \\ MARIANNA GRIMALDI
}

CESIFO WORKING PAPER NO. 1520

CATEgORY 6: MONETARY POLICY AND INTERNATIONAL FinANCE August 2005

\footnotetext{
An electronic version of the paper may be downloaded - from the SSRN website: www.SSRN.com

- from the CESifo website: www.CESifo-group.de
} 


\title{
THE IMPACT OF FX CENTRAL BANK INTERVENTION IN A NOISE TRADING FRAMEWORK
}

\begin{abstract}
In this paper we investigate the effects of central bank interventions (CBI) in a noise trading model with chartists and fundamentalists. We first estimate a model in which chartists extrapolate past returns and fundamentalists forecast a mean reverting dynamics of the exchange rate towards a fundamental value. Then, we investigate the role of central bank interventions in explaining the switching properties between the two types of agents. We find evidence that in the medium run, interventions increase the proportion of fundamentalists and therefore exert some stabilizing influence on the exchange rate.
\end{abstract}

JEL Code: F31, F33.

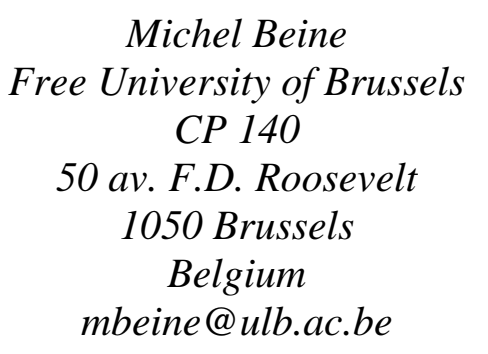

Paul De Grauwe

University of Leuven

Naamsestraat 69

3000 Leuven

Belgium

paul.degrauwe@econ.kuleuven.be

\author{
Marianna Grimaldi \\ Research Department \\ Sveriges Riksbank \\ 10337 Stockholm \\ Sweden \\ Marianna.grimaldi@riksbank.se
}

We would like to thank A. Benassy for transmitting the exchange rate misalignment data used in this paper. 


\section{Introduction}

Direct interventions in the foreign exchange (FX) market have often been used as a policy instrument by the major central banks . By sterilizing their operations, monetary authorities have used these interventions as a stabilisation tool independent of monetary policy. While some authorities like the US Federal Reserve have been increasingly reluctant to use central bank interventions (CBIs hereafter), other major central banks like the European Central Bank (ECB) or the Bank of Japan (BoJ) have conducted several rounds of interventions over the last five years. The ECB carried out four operations in the second part of the year 2000 in order to support the Euro against the other currencies. During the last decade, the BoJ has been extremely active, intervening in the market during more than three hundred days with the explicit aim of influencing the dynamics of the Yen against the USD.

Despite the wide use of direct interventions by the central banks, researchers (as well as policy makers) have questionned the effectiveness of such an instrument. Within the literature devoted to the conduct of foreign exchange rate policies, the issue of effectiveness is the one which has received the greatest attention. Recent surveys provided by Sarno and Taylor (2001) or Humpage (2003) offer a useful review of this strand of the literature. One problem in assessing whether interventions have delivered the intended goal is that the objectives followed by the central banks are rarely known by external researchers. Several possible objectives have been mentioned including influencing trend movements, reversing past trends, smoothing exchange rate volatility or creating monetary base through unsterilized operations. While a couple of international agreements like the Plaza agreement in 1985 and the Louvre agreement in 1987 provide some insight about the ultimate goal of these interventions, the objectives are likely to change over time and to differ across central banks. 1

A simple and direct criterion of effectiveness used in the empirical literature is whether the exchange rate level reacts to the central bank purchases or sales of foreign currency in the intended direction the day of the intervention (Baillie and Osterberg, 1997; Dominguez, 1998; Beine, Bénassy and Lecourt, 2002). The adoption of this criterion stems from the fact that the most fre-

\footnotetext{
${ }^{1}$ Lack of transparency in the FX policy is clearly one major source for identifying the explicit goals. The use of imprecise terms in central bank's statements also leads to some difficulty of interpretation.
} 
quent objective followed by central banks concerns the dynamics of the first moment of exchange rate returns. In general, the bulk of the empirical studies found that central bank interventions did not induce the intended changes in the exchange rate level. Some studies found even some moderate evidence of perverse results (i.e. currency depreciation following the purchase of this currency), which is difficult to rationalize (see nevertheless Bhattacharya and Weller, 1997). Quite recently however, new empirical approaches have provided more support for efficiency in the sense that the exchange rate was found to react significantly (and in the intended direction) to the central bank operation. Using intradaily data, Dominguez (2003) as well as Payne and Vitale (2003) indeed show that such an effect might show up in the very short run, i.e. within a few minutes after the occurrence of the operations. In a different perspective, accounting explicitly for the simultaneity issue, Kearns and Ribogon (2004) find more promising results at a daily frequency for the operations carried out by the Bank of Japan and the Reserve Bank of Australia.

While simple and straightforward, the use of this criterion of effectiveness raises two questions. First, the objective followed by the central bank might be less simple than influencing the level within the day or the hour of the intervention. For instance, the central bank might be willing to break a past depreciating or appreciating trend of its currency. In this case, insignificant results in terms of returns might lead to overemphasizing the poor performance of the operations. To tackle this point, some authors (Fatum and Hutchison, 2003; Morel and Teïleitche, 2004) have conducted event studies that allow to introduce more flexibility in terms of the possible objectives followed by the central bank(s). ${ }^{2}$ The second issue is the optimal horizon followed by central banks. While this horizon might differ across central banks and over time, central bank surveys (Neely, 2001) tend to show that central banks also care about the developments of the exchange rate beyond the day of the intervention. Promising outcomes generated by the intervention in the very short run might thus be meaningless for central bankers if they are reversed later on. Conversely, the use of successive interventions that might signal commitment of the central bank to defend the currency (such as the policy followed by the Bank of Japan in 2003 and 2004) might

\footnotetext{
${ }^{2}$ While interesting, we do not follow here this kind of approaches that in turn raise some questions about their implementation. There are in particular two critical issues associated to the use of event studies for assessing the impact of FX interventions. The first one is the definition of an event and in particular the definition of clustered operations that should be considered as one single event. The second point concerns the endogeneous definition of the event. For instance, if a particular central bank keeps intervening until the objective is reached, the use of event studies might lead to a bias in favour of efficiency. Interestingly, this general conclusion turns out to be more supported by this strand of the literature.
} 
lead to more favourable results that can be difficult to identify in the (very) short run.

In this paper, we adopt another criterion for efficiency of the FX central bank interventions. We consider a given central bank intervention as efficient if it moves the exchange rate in a direction consistent with the fundamental equilibrium exchange rate. Central banks often claim that their interventions aim at restoring the value of exchange rates to a level consistent with the fundamentals. While central banks pursue other goals, the specific objective of minimizing the degree of misalignement has been extensively included in loss functions used in theoretical analyses (see Vitale, 1999 as well as De Grauwe and Grimaldi, 2005 among others). The adoption of such a policy has been advocated by several authors including for instance Neely (2004) claiming that the central bank should act as a long-term speculator in the FX market. Theoretical analyses such as De Grauwe and Grimaldi (2005) also suggest that central bank interventions might drive the exchange rate in a direction consistent with fundamentals. In contrast to the analysis of simple regression coefficients capturing some contemporaneous impact, the adoption of this criterion allows for some role for central bank interventions in the medium run. To this aim, we assess the impact of interventions conducted by the Bundesbank (ECB after the inception of the Euro) and the Federal Reserve within a noise trading framework, i.e. a model allowing for the presence of two types of agents, namely chartists and fundamentalists. The noise trading framework has successfully been applied by authors to explain the discrepancy between the short and long-run exchange rate dynamics (Allen and Taylor, 1992; De Grauwe and Dewachter, 1993; De Grauwe and Grimaldi, 2004). It reflects the complex dynamics produced by the interaction of two types of agents whose existence has been empirically supported by the results of surveys of practitionners (Cheung and Wong, 2000 for instance).

The paper is organized as follows. In section 2 we present a model of the foreign exchange market in which two types of agents, chartists and fundamentalists, interact. We model foreign exchange market interventions within this model. The main prediction of the model is that sterilized intervention can be effective by making fundamentalist forecasting more profitable thereby increasing the importance of fundamentalist forecasting. In section 3 we test the prediction of this model. We first estimate a two-state Markov-switching model allowing for an exchange rate dynamics consistent with the forecasting rules of the chartists on the one hand and of the fundamentalists on the other hand. The role of central bank interventions is introduced through its 
impact on the dynamics of the first order transition probabilities across regimes and hence on the dynamics of the proportion of each type of agents. Section 4 briefly concludes.

\section{The underlying theory}

In this section we develop a simple exchange rate model. The model is based on De Grauwe and Grimaldi(2004). It consists of three building blocks. First, utility maximising agents select their optimal portfolio using a mean-variance utility framework. Second, these agents make forecasts about the future exchange rate based on simple but different rules. In this second building block we introduce concepts borrowed from the behavioural finance literature. Third, agents evaluate these rules ex-post by comparing their risk-adjusted profitability.

\subsection{The optimal portfolio}

We assume agents of different types $i$ depending on their beliefs about the future exchange rate. Each agent can invest in two assets, a domestic asset and foreign assets. The agents' expected utility can be represented by the following equation:

$$
U\left(W_{t+1}^{i}\right)=E_{t}^{i}\left(W_{t+1}^{i}\right)-\frac{1}{2} \mu V_{t}^{i}\left(W_{t+1}^{i}\right)
$$

where $W_{t+1}^{i}$ is the wealth of agent of type $i$ at time $t+1, E_{t}^{i}$ is the expectation operator, $\mu$ is the coefficient of risk aversion and $V_{t}^{i}\left(W_{t+1}^{i}\right)$ represents the conditional variance of wealth of agent $i$. The wealth is specified as follows:

$$
W_{t+1}^{i}=\left(1+r^{*}\right) s_{t+1} d_{i, t}+(1+r)\left(W_{t}^{i}-s_{t} d_{i, t}\right)
$$

where $r$ and $r^{*}$ are respectively the domestic and the foreign interest rates (which are known with certainty), $s_{t+1}$ is the exchange rate at time $t+1, d_{i, t}$ represents the holdings of the foreign assets by agent of type $i$ at time $t$. Thus, the first term on the right-hand side of (2) represents the value of the foreign portfolio expressed in domestic currency at time $t+1$ while the second term 
represents the value of the domestic portfolio at time $t+1^{3}$.

Substituiting equation (2) into (1) and maximising the utility with respect to $d_{i, t}$ allows us to derive the standard optimal holding of foreign assets by agents of type $i^{4}$ :

$$
d_{i, t}=\frac{\left(1+r^{*}\right) E_{t}^{i}\left(s_{t+1}\right)-(1+r) s_{t}}{\mu \sigma_{i, t}^{2}}
$$

where $\sigma_{i, t}^{2}=\left(1+r^{*}\right)^{2} V_{t}^{i}\left(s_{t+1}\right)$. The optimal holding of the foreign asset depends on the expected excess return (corrected for risk) of the foreign asset. The market demand for foreign assets at time $t$ is the sum of the individual demands, i.e.:

$$
\sum_{i=1}^{N} n_{i, t} d_{i, t}=D_{t}
$$

where $n_{i, t}$ is the number of agents of type $i$.

Market equilibrium implies that the market demand is equal to the market supply $Z_{t}$. Thus,

$$
Z_{t}=D_{t}
$$

The market supply is determined by the net current account and by the sales or purchases of foreign exchange of the central bank. We will assume that the net current account is exogenous. In section 2.4 we model these sales and purchases by the central bank. Substituting the optimal holdings (3) into the market demand (4) and then into the market equilibrium equation (5) and

\footnotetext{
${ }^{3}$ The model could be interpreted as an asset pricing model with one risky asset (e.g. shares) and a risk free asset. Equation (2) would then be written as

$W_{t+1}^{i}=\left(s_{t+1}+y_{t+1}\right) d_{i, t}+(1+r)\left(W_{t}^{i}-s_{t} d_{i, t}\right)$ where $s_{t+1}$ is the price of the share in $t+1$ and $y_{t+1}$ is the dividend per share in $t+1$.

${ }^{4}$ If the model is interpreted as an asset pricing model of one risky asset (shares) and a risk free asset, the corresponding optimal holding of the risky asset becomes

$$
d_{i, t}=\frac{E_{t}^{i}\left(s_{t+1}+y_{t+1}\right)-(1+r) s_{t}}{\mu \sigma_{i, t}^{2}}
$$

where $s_{t+1}$ and $y_{t+1}$ are the price and the dividend at $t+1$, respectively, and $\sigma_{i, t}^{2} \equiv V_{t}^{i}\left(s_{t+1}+y_{t+1}\right)$.
} 
solving for the exchange rate $s_{t}$ yields the market clearing exchange rate:

$$
s_{t}=\left(\frac{1+r^{*}}{1+r}\right) \frac{1}{\sum_{i=1}^{N} \frac{w_{i, t}}{\sigma_{i, t}^{2}}}\left[\sum_{i=1}^{N} w_{i, t} \frac{E_{t}^{i}\left(s_{t+1}\right)}{\sigma_{i, t}^{2}}-\Omega_{t} Z_{t}\right]
$$

where $w_{i, t}=\frac{n_{i, t}}{\sum_{i=1}^{N} n_{i, t}}$ is the weight (share) of agent $i$, and $\Omega_{t}=\frac{\mu}{\left(1+r^{*}\right) \sum_{i=1}^{N} n_{i, t}}$.

Thus the market clearing exchange rate is determined by the forecasts of the agents, $E_{t}^{i}$, about the future exchange rate, their respective weights $w_{i, t}$ and by the net supply of foreign assets $Z_{t}$.

Note also that the forecasts are weighted by their respective variances $\sigma_{i, t}^{2}$. When agent's $i$ forecasts have a high variance the weight of this agent in the determination of the market exchange rate is reduced.

\subsection{The forecasting rules}

We now specify how agents form their expectations of the future exchange rate and how they evaluate the risk of their portfolio.

We start with an analysis of the rules agents use in forecasting the exchange rate. We assume that two types of forecasting rules are used. One is called a "fundamentalist" rule, the other a "technical trading" rule 5 . The agents using a fundamentalist rule, the "fundamentalists", base their forecast on a comparison between the market and the fundamental exchange rate, i.e. they forecast the market rate to return to the fundamental rate in the future. In this sense they use a negative feedback rule that introduces a mean reverting dynamics in the exchange rate. Thus, the forecasting rule for the fundamentalists is :

$$
E_{t}^{f}\left(\Delta s_{t+1}\right)=-\psi\left(s_{t-1}-s_{t-1}^{*}\right)
$$

where $s_{t}^{*}$ is the fundamental exchange rate at time $t$, which is assumed to follow a random walk and $0<\psi<1$. We assume that the fundamental exchange rate is exogenous.

\footnotetext{
${ }^{5}$ The idea of distinguishing between fundamentalist and technical traders rules was first introduced by Frankel and Froot(1987).
} 
The timing of the forecasts is important. When fundamentalists forecast the future exchange rate they use publicly available information up to period $t-1$. This implies that fundamentalists make their forecasts before the market clearing exchange rate $s_{t}$ has been revealed to them ${ }^{6}$. This assumption is in the logic of the model used here in which agents do not know the full model structure. As a result, they cannot compute the market clearing exchange rate of time $t$ that will be the result of their decisions made in period $t^{7}$.

The timing assumption underlying the agents' forecasts in (7) allows us to derive the market clearing exchange rate in (6) as a unique price for which demand equals supply (see Brock and Hommes (1998)). An issue that arises here is how this timing assumption can be made consistent with the optimisation process described in the previous section. There we assumed that when computing their optimal holdings of foreign assets in period $t$, agents have information about the exchange rate in period $t$. The inconsistency is only apparent. The optimal holdings derived in equation (3) can be interpreted as a Marshalian demand curve in which an auctioneer announces a price, $s_{t}$. Agents then decide on their optimal holdings conditioned on this announced price. The auctioneer then collects the bids and offers, and computes the market clearing price. The latter is not in the information set of the agents when they make their forecasts for the exchange rate in period $t+1$.

The chartists are assumed to follow a positive feedback rule, i.e. they extrapolate past movements of the exchange rate into the future. The chartists' forecast is written as:

$$
E_{c, t}\left(\Delta s_{t+1}\right)=\beta \sum_{h=1}^{\infty} \rho_{h} \Delta s_{t-h}
$$

Here $E_{c, t}$ is the forecast made by the chartists using information up to time $t-1$, and $\beta$ is the coefficient expressing the degree with which chartists extrapolate the past change in the exchange rate; we assume that $0<\beta<1$ to ensure dynamic stability. Thus, the chartists compute a moving average of the past exchange rate changes and they extrapolate these changes into the future

\footnotetext{
${ }^{6}$ When we consider agents' expectations, at time $t$, of the exchange rate change we define $E_{i, t}\left(\Delta s_{t+1}\right) \equiv$ $E_{i, t}\left(s_{t+1}-s_{t-1}\right), i=f, c$.

${ }^{7}$ In an environment with fully and perfectly informed agents, agents know the underlying model and are capable of making such calculations. As a result, in such models agents use information about the exchange rate at time $t$.
} 
exchange rate change. We set $\rho_{h}=\left[(1-\rho) \rho^{h-1}\right]$. Note that this assumption of exponential decay allows us to rewrite equation (8) as

$$
E_{c, t}\left(\Delta s_{t+1}\right)=\rho E_{c, t-1}\left(\Delta s_{t}\right)+(1-\rho) \beta \Delta s_{t-1}
$$

Thus, technical traders take into account information concerning the fundamental exchange rate indirectly, i.e. through the exchange rate itself. Note that the same assumption about the timing of the information set is used here as in the case of fundamentalist forecasting.

We now analyse how fundamentalists and technical traders evaluate the risk of their portfolio. The risk is measured by the variance terms in equation (6), which we define as the weighted average of the squared (one period ahead) forecasting errors made by technical traders and fundamentalists, respectively. Thus we assume $\sigma_{i, t}^{2}=\left(1+r^{*}\right)^{2} V_{t}^{i}\left(s_{t+1}\right)$ where

$$
V_{t}^{i}\left(s_{t+1}\right)=\sum_{k=1}^{\infty} \theta_{k}\left[E_{t-k-1}^{i}\left(s_{t-k}\right)-s_{t-k}\right]^{2}
$$

and where $\theta_{k}=\theta(1-\theta)^{k-1}$ are geometrically declining weights $(0<\theta<1)$, and $i=f, c$. Note that eq. (10) can be rewritten in the recurrent form

$$
V_{t}^{i}\left(s_{t+1}\right)=\theta\left[E_{t-2}^{i}\left(s_{t-1}\right)-s_{t-1}\right]^{2}+(1-\theta) V_{t-1}^{i}\left(s_{t}\right)
$$

\subsection{Fitness of the rules}

The next step in our analysis is to specify how agents evaluate the fitness of these two forecasting rules. The general idea that we will follow is that agents use one of the two rules, compare their (risk adjusted) profitability ex post and then decide whether to keep the rule or switch to the other one. Thus, our model is in the logic of evolutionary dynamics, in which simple decision rules are selected. These rules will continue to be followed if they pass some "fitness" test (profitability test). 
In order to implement this idea we use an approach proposed by Brock and Hommes(1997) which consists in making the weights of the forecasting rules a function of the relative profitability of these rules, i.e. ${ }^{8}$ :

$$
\begin{gathered}
w_{c, t}=\frac{\exp \left[\gamma \pi_{c, t}^{\prime}\right]}{\exp \left[\gamma \pi_{c, t}^{\prime}\right]+\exp \left[\gamma \pi_{f, t}^{\prime}\right]} \\
w_{f, t}=\frac{\exp \left[\gamma \pi_{f, t}^{\prime}\right]}{\exp \left[\gamma \pi_{c, t}^{\prime}\right]+\exp \left[\gamma \pi_{f, t}^{\prime}\right]}=1-w_{c, t}
\end{gathered}
$$

where $\pi_{c, t}^{\prime}$ and $\pi_{f, t}^{\prime}$ are the risk adjusted net profits computed by technical traders and fundamentalists who forecast the exchange rate in period $t$ using information up to $t-1$, i.e. $\pi_{c, t}^{\prime}=\pi_{c, t}-\mu \sigma_{c, t}^{2}$ and $\pi_{f, t}^{\prime}=\pi_{f, t}-\mu \sigma_{f, t}^{2}$, while $\pi_{c, t}$ and $\pi_{f, t}$ are the net profits, to be defined later.

Equations (12) and (13) can be interpreted as switching rules. When the risk adjusted profits of the technical traders' rule increases relative to the risk adjusted net profits of the fundamentalists rule, then the share of agents who switches and uses technical trader rules in period $t$ increases, and vice versa. This parameter $\gamma$ measures the intensity with which the technical traders and fundamentalists revise their forecasting rules. With an increasing $\gamma$ agents react strongly to the relative profitability of the rules. In the limit when $\gamma$ goes to infinity all agents choose the forecasting rule which proves to be more profitable. When $\gamma$ is equal to zero agents are insensitive to the relative profitability of the rules. In the latter case the fraction of technical traders and fundamentalists is constant and equal to 0.5. Thus, $\gamma$ is a measure of inertia in the decision to switch to the more profitable rule. ${ }^{9}$

We depart from the Brock-Hommes approach in the way we define profits. In Brock-Hommes profits are defined as the total earnings on the optimal foreign asset holdings. We define the profits

\footnotetext{
${ }^{8}$ This specification of the decision rule is often used in discrete choice models. For an application in the market for differentiated products see Anderson, de Palma, and Thisse (1992). The idea has also been applied in financial markets, by Brock and Hommes (1998) and by Lux (1998).

${ }^{9}$ The psychological literature reveals that there is a lot of evidence of a "status quo bias" in decision making (see Kahneman, Knetsch and Thaler(1991). This implies $\gamma<\infty$. Thus we set $0<\gamma<\infty$. Our estimates of the Markov Switching model in section 3 fully support this conjecture.
} 
as the one-period earnings of investing $\$ 1$ in the foreign asset. More formally ${ }^{10}$,

$$
\pi_{i, t}=\left[s_{t-1}\left(1+r^{*}\right)-s_{t-2}(1+r)\right] \operatorname{sgn}\left[\left(1+r^{*}\right) E_{t-2}^{i}\left(s_{t-1}\right)-(1+r) s_{t-2}\right]
$$

Thus, when agents forecasted an increase in the exchange rate and this increase is realized, their per unit profit is equal to the observed increase in the exchange rate (corrected for the interest differential). If instead the exchange rate declines, they make a per unit loss which equals this decline (because in this case they have bought foreign assets which have declined in price).

Assuming the process of the fundamental exchange rate $s_{t}^{*}$ as exogenously given, the system of the dynamic equations $(6),(7),(8),(10),(12),(13),(14)$, some of which are high order equations, defines a high-dimensional nonlinear discrete-time model. The non-linear structure of the model does not allow for a simple analytical solution. As a result we have to use numerical simulation methods. This is done in De Grauwe and Grimaldi (2004) with a calibrated version of the model. These authors show that the model is capable of generating all the empirical "puzzles" observed in the foreign exchange market. These empirical puzzles are first and foremost the disconnect phenomenon (see Obstfeld and Rogoff (2000) who coined the term "disconnect puzzle"). De Grauwe and Grimaldi (2004) showed that the model is capable of mimicking this disconnect puzzle.

\subsection{Modelling official interventions in the foreign exchange market}

The model presented in the previous sections allows for an easy way to introduce the interventions of the central bank. The supply of foreign assets $Z_{t}$ in equation (6) is determined by the current account position, i.e. a surplus (deficit) in the current account increases (decreases) the supply of foreign assets. The supply of foreign assets, however, can also be influenced by the intervention

\footnotetext{
${ }^{10}$ where $\operatorname{sgn}[x]$ is defined as

$$
\operatorname{sgn}[x]=\left\{\begin{array}{cc}
1 & \text { for } x>0 \\
0 & \text { for } x=0 \\
-1 & \text { for } x<0
\end{array}\right.
$$
}

and $i=c, f$ 
activities of the central bank. More specifically, when the central bank sells foreign exchange it increases the supply of foreign assets $Z_{t}$. This will generally put downward pressure on the exchange rate. This can also be seen from equation (6): the sign of $Z_{t}$ is negative. Conversely when the central bank buys foreign exchange it reduces the supply of foreign assets putting upward pressure on the exchange rate.

It can be useful to analyse the impact effect of a surprise change in foreign assets on the exchange rate. We obtain this by isolating the effect of a change in $Z_{t}$ in equation (6). Setting the expectational terms equal to zero, and using the definition of $\Omega_{t}$ we obtain

$$
\Delta s_{t}=-\left(\frac{\mu}{1+r}\right) \frac{1}{\frac{w_{c, t}}{\sigma_{c, t}^{2}}+\frac{w_{f, t}}{\sigma_{f, t}^{2}}} X_{t}
$$

where $X_{t}=\Delta Z_{t} / N$, i.e. the supply of foreign assets per capita. As before, we have also assumed that there are only two types of agents, i.e. chartists and fundamentalists (subscipted by $\mathrm{c}$ and $\mathrm{f}$ respectively).

Equation (15) makes clear that the effect of a foreign exchange market intervention on the exchange rate will be difficult to predict ex ante because it depends on the weights the chartists and fundamentalists have in the market, together with the forecast errors they have been making in the past. In other words the effect of interventions will depend on the market structure and the risk perceptions at the time of the intervention. Since these factors change continuously, the effect of interventions will also change.

It should also be stressed that we analyze the effects of sterilized interventions here, i.e. interventions that are not allowed to affect domestic money market conditions, including the domestic interest rate. Thus we analyse interventions that do not affect the fundamentals. ${ }^{11}$

We investigate this question of the effectiveness of interventions assuming a simple intervention rule. The intervention rule we consider is one in which the central bank is continuously in the market smoothing the movements of the exchange rate by using a "leaning against the wind"

\footnotetext{
${ }^{11}$ The interventions carried out by the ECB (Bundesbank) and the Fed over the investigated period in the empirical analysis are reported by the central banks to have been sterelized.
} 
intervention rule. ${ }^{12}$ We specify this rule as follows:

$$
\Delta Z_{t}=\varsigma\left(\Delta s_{t-1}\right)
$$

where $\varsigma \geq 0$. Thus when the exchange rate increases (decreases), the central bank sells (buys) foreign exchange in the market so that the supply of foreign assets increases (decreases). The parameter $\varsigma$ measures the intensity with which the central bank performs these operations. Note that as in the case of the private agents the current exchange rate is not in the information set of the central bank. The current exchange rate is the market clearing exchange rate that will be the outcome of the decisions of both the private agents and the central bank, but is not yet known when agents make their decision.

We now implement this simple intervention rule by substituting equation (16) into equation (6) and solving the model numerically. We show some results of simulating the model in the time domain in figure (1) using a particular configuration of parameters (In De Grauwe and Grimaldi(2005) extensive senstitivity analyses are performed). Panel (a) shows the exchange rate in the absence of any intervention $(\varsigma=0)$. This is the free float solution It exhibits large movements of the exchange rate around its fundamental. The next two panels (b) and (c) show the exchange rate for increasing intensity of intervention. In panel (b) we assume that $\varsigma=0.01$ and in panel (c) we assume that $\varsigma=0.1$. We find that as $\epsilon$ is increased the exchange rate is forced to move more thightly around its fundamental. Thus it appears that this simple rule is capable of reducing the large disconnnection of the exchange rate from its fundamental in a free float environment. As a result the application of this rule ensures that the exchange rate better reflects the underlying fundamental.

The intuition behind this result is that the "leaning against the wind" strategy of the central bank reinforces the mean reverting dynamics in the market thereby strenghtening the hand of the fundamentalists at the expense of the 'trend chasers' (chartists). This stabilizes the market and

\footnotetext{
${ }^{12}$ This leaning-against-the wind type of behaviour has been supported by the estimation of empirical reaction functions for various central banks. See Almekinders and Eijffinger (1995) for the Bundesbank and more recently Ito (2003) for the Bank of Japan.
} 
reduces the probability of the emergence of bubbles. Thus the effect of this intervention is that the exchange rate follows the movements of the underlying fundamentals more closely ${ }^{13}$.

In order to shed additional light on the question of why a simple intervention rule can be effective, we show the average weight of the chartists and fundamentalists corresponding to the three scenarios in Table 1. We see that in the free float simulation the chartists have on average a weight of $90 \%$ in the market (the fundamentalists' weight is then $10 \%$ ), while in the scenario of intense intervention $(\varsigma=0.1)$ the average weight of the chartists declines to $76 \%$ (the average weight of fundamentalists increases to $24 \%$ ) Thus when the central bank successfully stabilizes the exchange rate so that it closely reflects the fundamentals, the fundamentalists on average have a higher share in the market than when the central bank does not intervene. Put differently, systematic interventions by the central bank change the structure of the foreign exchange market, i.e. they reduce the importance of chartists and increase the importance of fundamentalists. Thus, the "leaning agains the wind" intervention rule of the central bank creates an environment in which the fundamentalists are more active thereby keeping the exchange rate close to its fundamental. The reason why this is made possible is that the intervention rule increases the mean reversion forces in the market thereby making fundamentalists forecasting rules more profitable. We show this in Table 1 where we present the average profits of chartists and fundamentalists in three scenarios. We find that in the intervention scenarios $(\varsigma=0.01$ and $\varsigma=0.1)$ the fundamentalists make significantly more profits than in the free float scenario $(\varsigma=0)$. The reverse is true for the chartists' profits. This confirms that the intervention rule of the central bank increases the relative profitability of fundamentalist forecasting rules, thereby enhancing the position of fundamentalists in the market ${ }^{14}$. Thus the stabilizing effect of the intervention rule comes about indirectly, i.e. it makes fundamentalist forecasting more attractive thereby allowing the market to discover the fundamental value of the exchange rate more effectively.

Our results are consistent with the signalling channel of foreign exchange market interventions.that has been stressed by Dominguez(1998), Sarno and Taylor(2001) and others. In our model the interventions signal the central bank's commitment to avoid too large departures from

\footnotetext{
${ }^{13}$ In De Grauwe and Grimaldi(2005) we analysed the target intervention rule as proposed by Williamson and Miller (1987). The results are very similar to the simple leaning against the wind rule analysed here.

${ }^{14}$ Note that even in the intervention scenarios, chartism remains more profitable than fundamentalism.
} 
(a)

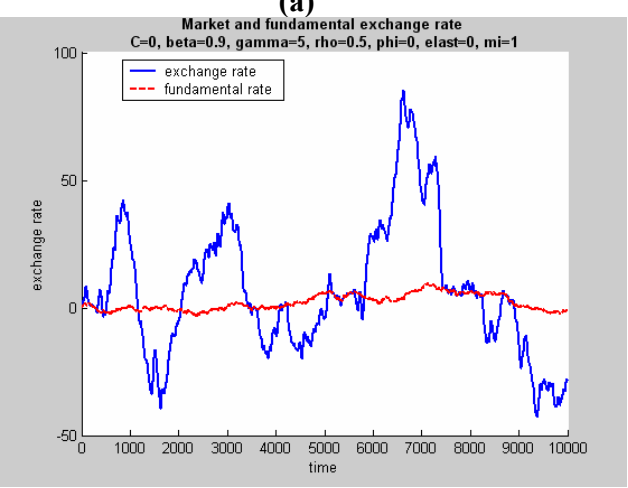

(b)

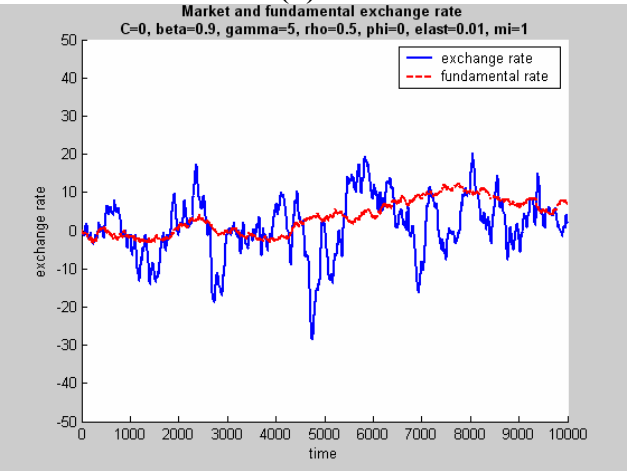

(c)

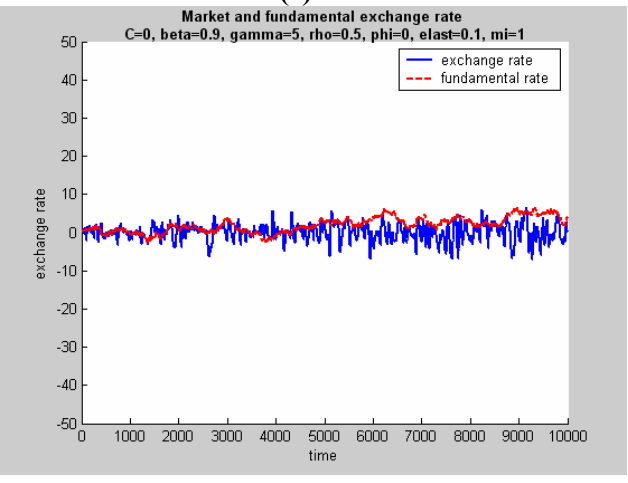

Figure 1: Simulated exchange rate under intervention rule 
the fundamental exchange rate. This signal has the effect of enhancing the influence of fundamental variables on the exchange rate.

\begin{tabular}{|l|l|l|l|}
\hline \multicolumn{4}{|c|}{ Mean profits and weights of fundamentalists and chartists } \\
\hline & $\varsigma=0$ & $\varsigma=0.01$ & $\varsigma=0.1$ \\
\hline mean profit fundamentalists & 0.0010 & 0.0045 & 0.0081 \\
\hline mean weight fundamentalists & 0.1 & 0.13 & 0.24 \\
\hline & & & \\
\hline mean profit chartists & 0.1099 & 0.0971 & 0.0888 \\
\hline mean weight chartists & 0.9 & 0.87 & 0.76 \\
\hline
\end{tabular}

Table 1 : Mean profits and weights of fundamentalists and chartists along with intervention intensity $(\varsigma)$

The previous results assume a rule based intervention policy. The question that arises is how a stochastic intervention by the central bank affects these results. Using the same model as the one presented here, De Grauwe and Grimaldi (2005) show that when the central bank intervenes in a random way, the effects of these interventions on the exchange rate are highly unpredictable. The reason why they obtain this result can readily be seen from equation (15). A random change in $\mathrm{X}$ has an unpredictable effect on the exchange rate because, as we argued earlier, it depends on market conditions prevailing at the time of the change in X. As a result, a given sale or purchase of foreign exchange can have very different effects on the exchange rate depending on the volatility in the market and the share of chartists at the time of the intervention. 


\section{The Empirical Investigation}

\subsection{The basic chartists-fundamentalists model}

In this section, we propose an empirical estimation of the impact of interventions, building on the theoretical framework developed in the previous section. The empirical counterpart of the theoretical model involves the modelling of chartist and fundamentalist traders whose proportions are ultimately affected by the occurrence of the central bank interventions. A natural way to do this is to specify a model with switching proporties between a chartist and a fundamentalist regimes.

We focus on the dynamics of the USD against the Euro (DEM before 1999) over a long period ranging from 1985 to 2003 . We work at the bi-weekly frequency. On the one hand, the respective behaviours of the chartists and fundamentalists are clearly identifiable in the medium run (see Sarno and Taylor, 2002). More precisely, typical chartists rule involve computations of moving average ranging from 14 to 200 days (see Neely, 2001 for instance). Fundamentalists basically react to deviations to equilibrium exchange rates which are computed at a macroeconomic frequency. On the other hand, central bank interventions are carried out at an intradaily frequency (the central bank typically reacts to short run exchange rate evolutions - see Neely, 2001) and the official data are available on a daily basis. The choice of the bi-weekly frequency for the data should therefore be seen as a compromise. It more or less matches the frequency that are typically used in previous estimations of this type of models (Vigfusson, 1997; Manzan and Westerhoff, 2005).

The estimated model is a two-regime Markov switching model. Each regime captures the behaviour of a particular type of agents trading in the FX market. At this stage, the switching properties of the model are not investigated further in the sense that the regime transition probabilities are supposed to be constant over time. ${ }^{15}$ We denote $e_{t}$ as the log of the Euro/USD exchange rate and we define the (bi-weekly) return as $r_{t}=100 *\left[\ln \left(e_{t}\right)-\ln \left(e_{t-1}\right)\right]$.

In the first regime, the chartist regime, in line with the theoretical model (see equation (8)), agents are supposed to use only past exchange rate developments to forecast future fluctuations

\footnotetext{
${ }^{15}$ We will relax this assumption mater on in section 3.4. when we will consider time-varying transition probabilities (TVTP).
} 
of the currencies. The general specification of the chartist regime is given by:

$$
r_{c, t}=C\left(r_{t-i}\right)+\epsilon_{c, t}
$$

where $r_{c, t}$ is the forecasted value of $r_{t}$ by chartists, $\epsilon_{c, t}$ is the error term peculiar to chartists and $C$ is the general function used by chartists for the purpose of forecasting.

In contrast to chartists, fundamentalists consider the exchange rate as reacting to misalignments of the current exchange rate level with the fundamental equilibrium value. The empirical specification is fully consistent with the theoretical forecasting rule for fundamentalists (equation $(7))$ :

$$
r_{f, t}=-\psi\left(e_{t-1}-f_{t-1}\right)+\epsilon_{f, t} .
$$

where $r_{f, t}$ is the forecasted value of $r_{t}$ by fundamentalists, $\epsilon_{f, t}$ is the error term peculiar to fundamentalists, $\psi$ is the parameter used by fundamentalists to forecast the exchange rate using the known value of the exchange rate misalignement and $f_{t-1}$ is the empirical countepart of the $\log$ of $s_{t-1}^{*}$ in (7) . Typically, parameter $\psi$ should be negative in this regime to capture a mean reverting behaviour of the exchange rate towards the fundamental value (depreciation required to correct overvaluation). ${ }^{16}$ In the Markov-switching model, the dynamics of the exchange rate is driven by the value of a latent variable $l_{t}$ that captures whether the prevailing regime is the chartist one $\left(l_{t}=c\right)$ or the fundamentalist one $\left(l_{t}=f\right)$. The special insight of the first-order Markov-switching model is that the dynamics of $l_{t}$ is driven by first-order transition probabilities. In the basic Markov Switching model (Hamilton, 1989 and 1994 for instance), these transition probabilities are assumed to be constant over time. In the case of two regimes, these transition probabilities are defined as :

\footnotetext{
${ }^{16}$ Of course, given the fact that the empirical specification slightly deviates from the theoretical model, we relax the assumption that $\psi$ is comprised between 0 and 1 .
} 


$$
\begin{aligned}
& p=\operatorname{Pr} o b\left(l_{t}=c \mid l_{t-1}=c\right) \\
& q=\operatorname{Pr} o b\left(l_{t}=f \mid l_{t-1}=f\right)
\end{aligned}
$$

In this model, $p$ captures the probability of remaining in the chartist regime from one period to the other. It is therefore a measure of the persistence of the regime from which it is possible to compute theoretically the expected number of periods during which the economy will be in this regime. ${ }^{17}$ For the sake of the future extension to the case of time-varying transition probabilities (TVTP), it may be useful to express $p$ and $q$ through a logistic specification of the type :

$$
\begin{aligned}
& p=1-\left(1+\exp \left(\pi_{0}\right)\right)^{-1} \\
& q=1-\left(1+\exp \left(\kappa_{0}\right)\right)^{-1}
\end{aligned}
$$

Notice that if the parameters $\pi_{0}$ and $\kappa_{0}$ expressed on the logistic scale take both zero values, then $p$ and $q$ equal 0.5 . In this case, the probability of remaining in the regime is equal to the probability of leaving the regime, suggesting that a Markov-switching approach is rather inappropriate to capture the dynamics of the exchange rate return. Although these specification tests may appear rather simple, Hamilton (1996) shows that $t$-tests applied to the transition probabilities of the type $\left[\hat{p}-p_{0}\right] / \hat{\sigma}_{\hat{p}}$ (where $p_{0}$ denotes the value of $p$ under the null and $\hat{\sigma}_{\hat{p}}$ the estimate of the standard error of $\hat{p}$ ) can be trusted, both asymptotically and in finite samples ${ }^{18}$.

\footnotetext{
${ }^{17}$ Indeed, the respective expected numbers of periods are equal to $1 /(1-p)$ and $1 /(1-q)$.

${ }^{18}$ Hamilton provides some Monte Carlo analysis for $\mathrm{T}=50$ and $\mathrm{T}=100$, i.e. for much smaller samples sizes than the ones considered here $(\mathrm{T}=498)$. The distributions of these $t$-statistics in small samples are found however to be skewed rightward.
} 


\subsection{Preliminary investigation}

In order to estimate model (17-19), we first need to tackle two points. The first one is the choice of an empirical measure of the fundamental equilibrium exchange rate $f_{t}$ that plays an important role in the definition of the fundamentalist regime. Previous work (Vigfusson, 1997; Manzan and Westerhoff, 2005) has typically used the PPP value as a measure of the equilibrium exchange rate. However, while interesting, PPP levels capture only one type of equilibrium and rely on the relevance of the law of one price. As an alternative, we use here recent estimates of Benassy et al. (2004) of these equilibrium exchange rates. The specific insight of these estimates is that they provide levels consistent with a joint equilibrium of all countries included in their sample (broadly speaking, the OECD countries). Furthemore, the equilibrium value is defined as the one consistent with external and internal balance of these economies.

We first compute for a given year the value of the nominal equilibrium exchange rate for the Eurozone in terms of USD from the misalignement values estimated by Bénassy et al. (2004) using the average value of the nominal exchange rate over the year. Since we compute misalignment values at much higher frequencies, we smooth this equilibrium value by interpolation in order to get rid of the artificial jumps due to changes of the calendar year. We then compute misalignment levels at the bi-weekly frequency by computing the distance of the (log of) the exchange rate from (the $\log$ of) this smoothed value of the equilibrium. ${ }^{19}$ Figure 3 plots the evolution of the smoothed misalignement degree of the Euro against the dollar over the sample period (positive values refer to Euro undervaluation). From the figure, one can identify two distinct periods of dollar overvaluation: the first one ranges from the beginning of the sample (January 1985) to the end of 1986; the second one begins in mid 1998 and persists until the end of the sample (May 2003).

\footnotetext{
${ }^{19}$ As for the exchange rate quotation, we use values observed on Fridays at 21.00 GMT+1 physical time. This choice ensures that interventions conducted by both central banks during the two last weeks occur before the quotation of the rate, assuming implicitely that these interventions take place on their own local markets. This assumption is supported by the evidence provided by Dominguez (2004) concerning the timings of the reported FX. operation
} 


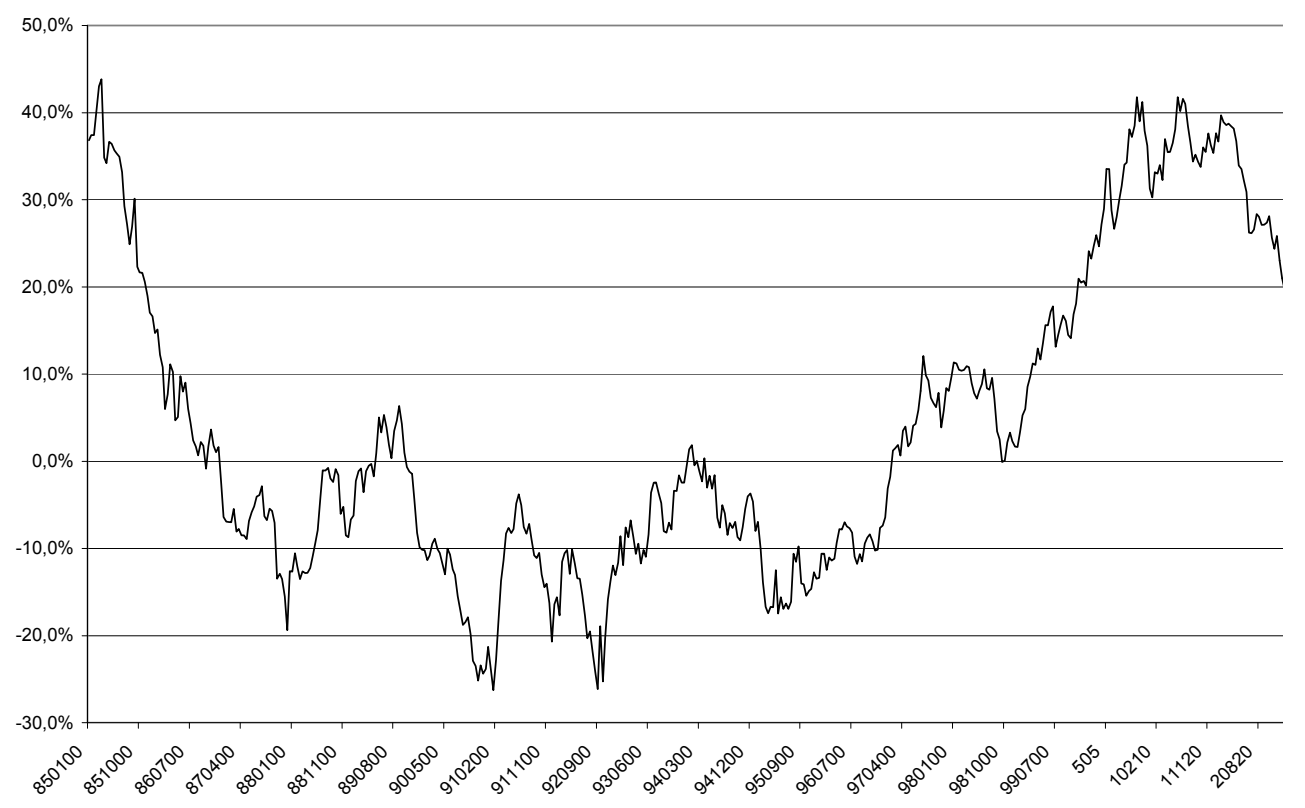

Figure 3. Misalignement of Euro against the USD (in percents)

The second issue is the exact nature of the $C$ function in the chartist regime (equation(17)). Chartists are usually reported to use a complex set of moving average rules leading to heterogeneous strategies across agents. This heterogeneity makes the identification of the agregate chartist forecasting rule quite cumbersome. Since chartist behaviour is not directly observable, there is a large number of admissible specifications for equation (17), which need to be evaluated. The retained specification should be therefore selected on the basis of data adjustment. As a premiminary check, we have estimated simple AR-GARCH models of the following type:

$$
\begin{aligned}
r_{t} & =r_{0}+\sum_{i=1}^{g} \rho_{i} r_{t-i}-\lambda\left(e_{t-1}-f_{t-1}\right)+\epsilon_{t} \\
\sigma_{t}^{2} & =\omega+\varphi \epsilon_{t-1}^{2}+\eta \sigma_{t-1}^{2} .
\end{aligned}
$$

where $r_{t}$ is the return of the DEM/USD exchange rate, $\sigma_{t}^{2}$ is the conditional variance and $r_{0}, \rho_{i}, \lambda, \omega, \varphi$ and $\eta$ are parameters to be estimated. ${ }^{20}$ We find reasonable evidence of a mean

\footnotetext{
${ }^{20}$ In order to save place, we do not report the estimated values for $r_{0}, \rho_{i}, \omega, \varphi$ and $\eta$ but these acn be obtained upon request.
} 
reverting behaviour of $r_{t}$ towards the equilibrium level with $\lambda$ equal to a value close to 1.35 and a significance level slightly above 5 percents. We do not find any evidence of significant autoregressive coefficients for $g$ up to 10 . This is hardly surprising given that the model is a single regime model capturing some mixture of the dynamics between the chartist and the fundamentalist regimes. Nevertheless, almost all coefficients turn out to be positive, suggesting that agents make use of extrapolative moving average rules capturing the medium-run evolution of exchange rates. Replacing the autoregressive part $\sum_{i=1}^{g} \rho_{i} r_{t-i}$ by the past cumulated returns $\left[e_{t-1}-e_{t-(p+1)}\right]$, we find limited evidence of a positive relationship. In particular, we find that for $g=4$, this term exibits a positive relationship with a $p$-value slightly above 10 percents. This might suggest that on average chartists extrapolate returns using a two-months window. We build on this preliminary evidence to find a suitable specification to equation(17) in the chartist regime.

\subsection{The constant transition probabilities case}

Based on the preliminary evidence and after testing competing models, the retained specification for the chartist equation is :

$$
r_{c, t}=\alpha_{1}\left(e_{t-1}-e_{t-5}\right) 1_{\left\{\left|r_{t-1}\right|<\bar{b}\right\}}+\alpha_{2}\left(e_{t-1}-e_{t-5}\right) 1_{\left\{\left|r_{t-1}\right|>\bar{b}\right\}}+\epsilon_{c, t}
$$

where 1 is the indicator function taking 1 if the condition within brackets is satisfied, 0 otherwise and $\bar{b}$ is some constant threshold. In this specification, chartists use past exchange rate trends defined over the last four periods (last two months) in a non linear way. The extrapolation rate is different whether short run volatility (captured by $\left|r_{t-1}\right|$ ) is below or above some threshold. To measure this threshold $\bar{b}$, we choose the average value of $\left|r_{t-1}\right|$ over the entire sample. ${ }^{21}$ This specification therefore captures the fact that chartists will behave differently whether the level of exchange rate volatility has been relatively high or not.

The Markov-switching regimes are estimated by the Expected Maximum Likelihood (EML) procedure (see for details Hamilton 1994). Basically, the EML estimation relies on the maximiza-

\footnotetext{
${ }^{21}$ Note that given the fact that exchange rate volatility is often clustered over time, $\left|r_{t-1}\right|$ will also proxy the contemporaneous level of volatility.
} 
tion of the log-likelihood function $\sum_{t=1}^{T}\left[\operatorname{Ln}\left(\Gamma\left(r_{t} \mid \Theta_{t}\right)\right]\right.$ in which $\Gamma$ is the conditional density of $\epsilon_{t}$ and $\Theta_{t}$ the information set at time $t$. In the EML procedure, the log-likelihood is computed from the sum of the log-likelihood values conditional upon each regime:

$$
\begin{gathered}
\operatorname{Ln}\left(\Gamma\left(r_{t}|| \Theta_{t}\right)\right)= \\
\operatorname{Ln} \sum_{i=1}^{S} \sum_{j=1}^{S}\left(\Gamma\left(r_{t} \quad \mid \quad \Theta_{t}, l_{t}=i, l_{t-1}=j\right) \operatorname{Pr}\left(l_{t}=i, l_{t-1}=j \mid \Theta_{t}\right) .\right.
\end{gathered}
$$

It is assumed that $\Gamma$ is gaussian. ${ }^{22}$ It should be stressed that for assessing the relevance of the two-regime model against a one-regime model, the standard conditions are not fulfilled to carry out the usual likelihood ratio tests (LRT). Several solutions have been proposed (see for instance Hansen 1992), including the adjustment of critical values proposed by Garcia (1998) for a set of specific two-regime models. When these adjusted critical values are not available, one has to rely on auxiliary tests.

Table 2 reports the estimates of the basic chartist-fundamentalist model for two alternative specifications. Several comments are in order. First, the model estimations clearly identify the fundamentalist regime. The $\psi$ parameter is significantly positive, suggesting a mean-reverting behaviour of $e_{t}$ towards its fundamental value $f_{t}$. This finding is highly robust to alternative specifications and to the extension of the model to time-varying transition probabilities (see section 3.4). Second, the model estimates suggest that in the chartist regime, agents tend to extrapolate past trends only when the short-run volatility is relatively high $\left(\alpha_{2}>0\right)$. The $p$-value of this parameter is slightly above the $5 \%$ significance level (p-values of 5.3 and 5.7 percents for respectively specification (1) and specification (2)). In contrast, when the level of short-run volatility is historically low, chartists see the exchange rate as following a random walk: $\alpha_{1}$ is insignificantly different from zero and is therefore excluded in the second specification (last column in table 1). These results suggest that the chartist regime is at best non stabilising for the exchange rate and can be even destabilizing in relatively turbulent markets. Importantly, the results are consistent with the

\footnotetext{
${ }^{22}$ For the estimation of the smoothed probabilities $\operatorname{Pr}\left(s_{t}=i \mid \Omega_{t}\right)$, we rely on the algorithm developped by Kim (1994).
} 


\begin{tabular}{|c|c|c|c|c|}
\hline & (1) & & (2) & \\
\hline \multirow{2}{*}{$\alpha_{1}$} & 0.018 & & - & \\
\hline & [0.039] & & & \\
\hline \multirow[t]{2}{*}{$\alpha_{2}$} & 0.987 & * & 1.007 & * \\
\hline & [0.510] & & [0.529] & \\
\hline \multirow[t]{2}{*}{$\psi$} & 1.574 & ** & 1.592 & ** \\
\hline & {$[0.785]$} & & {$[0.778]$} & \\
\hline \multirow[t]{2}{*}{$\sigma_{c}^{2}$} & 2.583 & *** & 2.605 & *** \\
\hline & [0.235] & & {$[0.246]$} & \\
\hline \multirow[t]{2}{*}{$\sigma_{f}^{2}$} & 1.658 & *** & 1.665 & *** \\
\hline & [0.161] & & {$[0.160]$} & \\
\hline \multirow[t]{2}{*}{$\pi_{0}$} & 2.620 & $* * *$ & 2.516 & $* * *$ \\
\hline & [1.238] & & [1.214] & \\
\hline \multirow[t]{2}{*}{$\kappa 0$} & 2.687 & $* * *$ & 2.658 & $* * *$ \\
\hline & [0.916] & & [0.869] & \\
\hline \multirow[t]{2}{*}{$p$} & 0.932 & & 0.925 & \\
\hline & [0.078] & *** & {$[0.084]$} & *** \\
\hline \multirow[t]{2}{*}{$q$} & 0.935 & & 0.935 & \\
\hline & {$[0.055]$} & *** & {$[0.053]$} & *** \\
\hline Nobs & 981 & & 981 & \\
\hline LogLik & -1042.93 & & -1043.03 & \\
\hline \multicolumn{5}{|c|}{ tandard errors of expected maximum likelihood estimates are in brackets. } \\
\hline \multicolumn{5}{|c|}{${ }^{* * *},{ }^{* *}$ and ${ }^{*}$ refer to significance at $1 \%, 5 \%$ and $10 \%$ nominal levels } \\
\hline
\end{tabular}

Figure 2: Table 2. The basic chartist-fundamentalist model: Euro-USD January 1985- May 2003 
theoretical framework in which chartists are supposed to follow a positive feedback rule (equation (8)). Third, our estimates of the error variances suggest that on average, the chartist regime is riskier than the fundamental one. Finally, regarding the transition probabilities, the estimates suggest the existence of a significant degree of persistence within each regime, with probabilities of remaining in the previous regime amounting to about 0.93 for both types of agents. The ergodic (long-run) probabilities (implied by the estimates of $p$ and $q$ in specification (1)) amount to 0.498 and 0.502 in respectively the chartist and fundamentalist regimes, suggesting that on average, the proportion of both type of agents is equal. Of course, this does not rule out periods in which one regime prevails. Nevertheless, examining the smoothed probabilities that capture the probability of being in both regimes, we do not find any evidence of proportions of chartists or fundamentalists equal to 1. For the sake of illustration, the highest proportion of chartists amounts to 0.89 . We find a very small proportion of chartists in the very beginning of the sample (below 0.01) but these proportions are never equal to zero. In other terms, the model suggests that the dymamics of the exchange rate is always a mixture of the dynamics intrinsically related to both regimes.

\subsection{The role of interventions}

\subsubsection{The TVTP model}

In specification (22-23), the transition probabilities of remaining in a particular regime depend only on the previous state of the economy $\left(l_{t-1}\right)$, i.e. the nature of the regime prevailing during the previous period. One possibility to capture the impact of exogenous variables is to make these transition probabilities dependent on these variables. In our analysis, we introduce central bank interventions that take place during the two preceding weeks. While specific, this extension is consistent with the theoretical model exposed in section 2. Indeed, in the chartists-fundamentalists framework, the dynamics of the exchange rate is intrinsically related to the proportion of each type of agents. These proportions depend primarily on the profitability of the respective forecasting rules (equations (12) and (13)). In turn, the relative profitabilities are affected by the occurrence of the central bank interventions in the FX markets. As a result, as suggested by the simulation outcomes, the proportions of chartists and fundamentalists are affected by the central bank purchases and sales of foreign currency. Through the extension to time-varying transition 
probabilities that depend on these interventions, our empirical modelling closely reflects the way the impact of FX interventions is captured in the theoretical model.

To implement the TVTP estimation, we followe Filardo (1994) as well as Diebold, Lee and Weinbach (1994) and use a logistic specification. In this case, denoting by $I_{i, t-1}$ intervention of type $i$ which has taken place between $t-1$ and $t$ and building on equations (21-22), we extend the chartist-fundamentalist model as :

$$
\begin{aligned}
& p=\operatorname{Pr} o b\left(l_{t}=c \mid l_{t-1}=c, I_{i, t-1}\right)=1-\left(1+\exp \left(\pi_{0}+\sum_{i=1}^{m} \pi_{i} I_{i, t-1}\right)^{-1} .\right. \\
& q=\operatorname{Pr} o b\left(l_{t}=f \mid l_{t-1}=f, I_{i, t-1}\right)=1-\left(1+\exp \left(\kappa_{0}+\sum_{i=1}^{m} \kappa_{i} I_{i, t-1}\right)^{-1} .\right.
\end{aligned}
$$

The full model is made of equations (18-24-26-27).

\subsubsection{CBI Data}

The central bank intervention data used in this paper are direct purchases and sales of foreign currencies carried out by the Fed and the Bundesbank (ECB after the inception of the Euro) over the period ranging from 1 January 1985 to 31 May 2003. We use daily official interventions, i.e. interventions released by the central banks themselves. These exclude false rumours of interventions. Given the available statistical information, there are several ways through which one can capture the activity of central banks in the FX markets.

First, one can measure central bank's activity through the total amounts sold or purchased on the markets. As an alternative, one can capture the presence of these central banks by either dummy variables or by the total number of intervention days over the period under investigation. Here, we disregard the amounts and use the latter approach. There are two basic reasons for which using total amounts can be misleading. First, these amounts are released with a lag of several months (usually between 3 and 6 months) by central banks and news wire reports clearly show that currency traders do usually a very bad job in estimating the level of currency transactions 
from the observation of the flow orders. Second, along the signalling channel, amounts of interventions should exert a very non linear effect on the reaction of currency traders, which leads to a cumbersone empirical identification of these effects. ${ }^{23}$

The second choice regarding the measure of central bank's activity is whether one should use perceived rather than official interventions. The difference between these categories gives the number of secret (i.e. unreported) interventions carried out by the monetary authorities. In this respect, Beine and Lecourt (2004) propose a new method based on newswire reports to disentangle official interventions into reported (i.e. perceived) operations and secret ones. As usual in this literature, the decomposition relies on the information available to traders the day of the intervention. Since we use data at the bi-weekly frequency, such a decomposition might nevertheless be misleading. Some operations which are unknown to traders the day they were carried out (and thus classified as secret interventions) might be disclosed a few days later through rumours or confirmation statements given by officials. However, using the mere number of official daily intervention days might also be misleading in the sense that the exact number of interventions over the two previous weeks might also be unknown. As a result, we use two alternative measures. The first one computes the number of offficial intervention days over the two previous weeks by a given central bank. The second one uses a dummy variable capturing whether a particular central banks was active or not in the market during the previous period.

A final point concerns the distinction between concerted and unilateral operations. A substantial number of studies have disentangled the FX operations between unilateral ones (conducted by a single central bank) and coordinated ones (simultaneous operations of the two central banks in the same market). This distinction stems from two reasons. First, there is some evidence (Catte et al., 1994) that coordinated operations might exert different impacts from unilateral interventions. The signalling theory that emphasizes the information content embedded by these operations also implies such an asymmetric effect. Nevertheless, this distinction has been especially relevant for studies using high frequency data and it is less clear that such a decomposition is needed when using bi-weekly data. From a statistical point of view, the distinction between concerted and unilateral operations also allows to reduce the observed degree of correlation between the intervention

\footnotetext{
${ }^{23}$ See Beine and Szafarz (2004) for an attempt on the YEN/USD market. In contrast to the BoJ interventions, the daily size of the Fed and the Bundesbank operations does not vary significantly over the investigated period.
} 
variables and to reduce the problems of multicollinearity (see Beine et al., 2003 for some extensive evidence on weekly data). This high degree of correlation is due to the important proportion of concerted operations observed especially during the first part of the sample. This is particularly important when measuring central bank activity by the total number of intervention days over the previous period. As a result, we use two alternative measures of central bank activity. As a first measure, we use the number of intervention days of both central banks (ECB and the Fed), whether they are coordinated or not. As a second measure, we disentangle these operations into unilateral operations of each central bank and concerted operations.

\subsection{The results}

Table 3 reports the estimation results of the full chartists-fundamentalists model with transition probabilities depending on the central bank interventions $I_{i, t-1}$. In line with the earlier discussion, each column reports the results obtained with a different measure for $I_{i, t-1}$. Column (1) reports the results obtained with central bank activity measured by the total number of intervention days of the Fed (268 intervention days) and the Bundesbank (318 intervention days), irrespective of whether they are concerted or unilateral. As expected, given the share of coordinated interventions (161 intervention days) this results in a high degree of correlation (0.724), which in turn may lead to imprecise estimates of the impact $\left(\pi_{1}, \pi_{2}, \kappa_{1}\right.$ and $\kappa_{2}$ coefficients). This degree of correlation is very much reduced when measuring central bank activity by the number of unilateral and concerted operations. ${ }^{24}$ The results specific to this specification are reported in column (2) of Table 3. Results of column (3) are obtained with the same specification, with the unilateral Fed interventions excluded to increase efficiency. Finally, results of column (4) are obtained with central bank activity captured by dummies rather than by the number of intervention days over the previous two-weeks period. ${ }^{25}$

\footnotetext{
${ }^{24}$ The correlation between concerted operations and unilateral Fed interventions (resp. BB interventions) amounts to 0.286 (resp. 0.391). The correlation between unilateral operations of the Fed and those of the Bundesbank is equal to 0.131 .

${ }^{25}$ Using this measure, we observe 54, 45 and 62 occurrences for respectively the concerted, the Fed and the Bundesbank interventions.
} 


\begin{tabular}{|c|c|c|c|c|c|c|c|c|}
\hline & $(1)$ & & $(2)$ & & (3) & & $(4)$ & \\
\hline \multirow[t]{2}{*}{$\alpha_{1}$} & -0.009 & & 0.003 & & 0.006 & & -0.006 & \\
\hline & [0.039] & & {$[0.030]$} & & [0.032] & & [0.040] & \\
\hline \multirow[t]{2}{*}{$\alpha_{2}$} & 0.800 & & 0.890 & ** & 0.834 & * & 0.925 & * \\
\hline & [0.535] & & [0.438] & & [0.430] & & {$[0.504]$} & \\
\hline \multirow[t]{2}{*}{$\psi$} & 1.759 & *** & 1.996 & *** & 1.972 & $\star * *$ & 1.592 & ** \\
\hline & [0.645] & & [0.653] & & {$[0.652]$} & & [0.635] & \\
\hline \multirow[t]{2}{*}{$\sigma_{c}^{2}$} & 2.699 & *** & 2.555 & *** & 2.538 & *** & 2.723 & *** \\
\hline & {$[0.221]$} & & {$[0.166]$} & & {$[0.154]$} & & [0.192] & \\
\hline \multirow[t]{2}{*}{$\sigma_{\mathrm{f}}^{2}$} & 1.812 & *** & 1.709 & *** & 1.700 & *** & 1.775 & *** \\
\hline & [0.103] & & [0.121] & & {$[0.122]$} & & [0.089] & \\
\hline \multirow[t]{2}{*}{$\pi_{0}$} & 4.331 & *** & 3.921 & *** & 3.966 & *** & 4.928 & *** \\
\hline & {$[0.767]$} & & [0.780] & & {$[0.819]$} & & {$[1.087]$} & \\
\hline \multirow[t]{2}{*}{$\pi_{1}[\mathrm{Fed}, \mathrm{c}]$} & 0.363 & & -0.071 & & - & & 5.093 & \\
\hline & [0.599] & & {$[0.414]$} & & & & [4.934] & \\
\hline \multirow[t]{2}{*}{$\pi_{2}[\mathrm{ECB}, \mathrm{c}]$} & -0.924 & ** & -0.830 & ** & -0.891 & ** & -3.989 & *** \\
\hline & [0.439] & & [0.383] & & [0.372] & & [1.453] & \\
\hline \multirow[t]{2}{*}{$\pi_{3}[$ Coord,c] } & - & & -0.644 & & -1.157 & & -3.809 & ** \\
\hline & & & [0.551] & & [1.064] & & [1.760] & \\
\hline \multirow[t]{2}{*}{$\kappa_{0}$} & 6.066 & * & 4.723 & *** & 4.784 & *** & 16.576 & \\
\hline & [3.212] & & [1.815] & & [1.673] & & [40.207] & \\
\hline \multirow[t]{2}{*}{$\kappa_{1}[$ Fed,f] } & -2.423 & & -0.395 & & - & & -16.375 & \\
\hline & [2.005] & & [0.433] & & & & [40.163] & \\
\hline \multirow[t]{2}{*}{$\kappa_{2}[\mathrm{ECB}, \mathrm{f}]$} & -0.086 & & -1.051 & & -0.200 & & -15.247 & \\
\hline & [0.923] & & [0.990] & & {$[0.682]$} & & [40.219] & \\
\hline \multirow[t]{2}{*}{$\kappa_{3}[$ Coord,f $]$} & - & & -1.060 & & -1.807 & & -15.078 & \\
\hline & & & [0.681] & & [1.220] & & [40.211] & \\
\hline Nobs & 981 & & 981 & & 981 & & 981 & \\
\hline LogLik & -1040.35 & & -1040.13 & & -1040.68 & & -1040.13 & \\
\hline p-value LRT & 0.27 & & 0.47 & & 0.34 & & 0.09 & \\
\hline \multicolumn{8}{|c|}{ standard errors of expected maximum likelihood estimates are in brackets. } & \\
\hline
\end{tabular}

Table 3. FX Interventions in the chartist-fundamentalist model: Euro-USD, January 1985, May 2003.

On the whole, we find that the occurrence of interventions has induced some increase in the proportion of fundamentalists, especially when these operations took place when the chartist regime prevailed. Indeed we find some evidence that the transition probability of remaining in the chartist regime significantly decreases as a result of the occurrence of the FX interventions. This is the case for the Bundesbank interventions $\left(\pi_{2}<0\right)$, regardless of the way they are measured. 
We observe the same effect for coordinated interventions when central bank activity is captured through a single dummy variable (see $\pi_{3}<0$ in column 4 ). This may suggest that traders pay attention to the fact that the central banks were active during the past two weeks rather than to the pure number of occurrences of this type of operation. ${ }^{26}$ Importantly, we do not find any evidence of some effect of interventions driving the exchange rate towards a value consistent with the chartist dynamics. ${ }^{27}$

An interesting finding of the analysis concerns the asymmetric effects between unilateral operations of the Fed and the Bundesbank. Indeed, we find evidence in favor of efficiency for the unilateral opertations of the Bundesbank and to a lesser extent the concerted interventions. In contrast, the unilateral operations of the Fed display weak effects in terms of the dynamics of chartists and fundamentalists. In the theoretical model, the adoption of an intervention rule that aims at reducing the degree of misalignement results in higher efficiency compared to interventions conducted in a random way. Almekinders and Eiffinger (1995) find that the Bundesbank intervened in reaction to deviations of the exchange rate from a target computed as the moving average over past values of the exchange rate. To the extent that this target is similar to the equilibrium exchange rate, this suggests that the Bundesbank did not behave very differently compared with the representative central bank in the theoretical model. As for the recent period, the three unilateral interventions of the ECB in November 2000 took place when the Euro was obviously undervalued with respect to the dollar. While Almekinders and Eiffinger (1995) also found that the Fed adopted a leaning-against-the-wind policy before 1990, they also document a stronger reaction of the US authorities to exchange rate volatility. This suggests that the Fed is less keen to adop a specific intervention rule aiming at reducing the degree of misalignement. This behaviour was confirmed in the nineties during which the official motivation to intervene was more to react to market disorders. ${ }^{28}$

\footnotetext{
${ }^{26}$ Once more, it should be stressed that traders are not necessarily able to observe the total number of operations in the short run. This is especially the case during the first part of the sample in which the quality of news wire services was relatively lower.

${ }^{27}$ For the central bank interventions taking place when the fundamentalist regime prevails, while negative, the impact is never significant due to the very high value of uncertainty obtained in the parameter estimation. This is for instance striking in column 4 of Table 2 (see $\kappa_{1}, \kappa_{2}$ and $\kappa_{3}$ parameters). Such a blowing up of the standard deviation might reflect that very few interventions occur when such a regime prevails, leading to very poor estimations of these parameters.

${ }^{28}$ Interestingly, the quaterly report on the Treasury and Federal Reserve foreign exchange operations issued after the last intervention in 2000 states that the reason to intervene in support of the Euro was the prevailing excess exchange rate volatility.
} 
To sum up, we find that if there is some effect of these operations at a two-weeks horizon, the purchases or sales carried out by the central bank tend to push the exchange rate in a direction consistent with the fundamentals. This can be interpreted to mean that interventions were on average effective in the medium run. This contrasts with the usual claim that interventions are not effective (and even counterproductive) since they hardly manage to move the exchange rate in the intended direction.

\section{Conclusion}

This paper aims at revisiting the issue of effectiveness of central bank interventions in the FX market. As an alternative to what has been used in the literature, we define an effective operation as the one driving the exchange rate closer to its fundamental value. To this aim, we analyze the effects of a central bank intervention rule within a theoretical framework capturing the interaction of the behaviour of chartist and fundamentalist traders in the FX market. The intervention is found to affect the relative profitability of the strategies developed by both type of agents, leading to an increase in the proportion of fundamentalist traders and hence a market exchange rate closer to the fundamental level.

We empirically assess the effectiveness of the interventions and focus on the effects of the operations carried out by the ECB (Bundesbank before the inception of the Euro) and the Federal Reserve in the Euro/USD market. We test to what extent the occurrence of the central bank interventions tended to affect the transition probabilities relative to the chartist and the fundamentalist regime. We find some evidence that in the medium run, the occurrence of some unilateral and to a lesser extent coordinated interventions led to a decrease in the proportion of chartists. To the extent that the chartist traders are found to extrapolate past exchange rate movements to forecast future values, we find that the interventions have the effect of bringing the exchange rate more in line with a value consistent with the fundamentals in the economy.

We take the view that our criterion of effectiveness of interventions is consistent with the general objectives pursued by central banks. It abstracts from simple criteria used before like the contemporaneous impact that can be inconsistent with the medium run goals followed by monetary authorities. Interestingly, while the bulk of previous studies often concluded against 
the effectiveness of the central bank interventions in the short run, our findings tend to give more support in favour of a reasonable degree of effectiveness in the medium run.

\section{References}

[1] Allen, H. and Taylor, M.P. (1990), Charts, Noise and Fundamentals in the London Foreign Exchange Marlet, The Economic Journal, 100, 49-59.

[2] Almekinders, G.J., and S.C.W. Eijffinger, 1996, A Friction Model of Daily Bundesbank and Federal Reserve Interventions, Journal of Banking and Finance, 20, 13651380.

[3] Baillie, R.T., Osterberg, W.P., 1997. Why do Central banks Intervene ?, Journal of International Money and Finance, 16 (6), 909-919.

[4] Bhattacharya, U. and P. Weller, 1997, The Advantage of Hiding one's hand: Speculation and Central Bank Intervention in the FX Market, Journal of Monetary Economics, 39, 251-277.

[5] Beine, M., A. Bénassy-Quéré, and C. Lecourt, 2002, Central Bank Intervention and Foreign Exchange Rates: New Evidence from FIGARCH estimations. Journal of International Money and Finance, 21, 115-144.

[6] Beine, M., Laurent, S. Lecourt C, 2000. Central Bank Intervention and Exchange Rate Volatility: Evidence from a Regime Switching Analysis, European Economic Review, 47 (5), 891-911.

[7] Beine, M. and C. Lecourt, 2004, Reported and Secret interventions in the Foreign Exchange Markets. Finance Research Letters, 1(4), 215-225.

[8] Bénassy-Quéré, A. , P. Duran-Vigneron, A. Lahrèche-Revil and V. Mignon, 2004, Burden Sharing and Exchange Rate Misalignments within the Group ofTwenty. CEPII Working paper $\mathrm{n}^{\circ} 2004-13$.

[9] Brock, W., and Hommes, C.,1998, Heterogeneous beliefs and routes to chaos in a simple asset pricing model, Journal of Economic Dynamics and Control, 22, 1235-1274. 
[10] De Grauwe, P. and Dewachter, H., A Chaotic Model of the Exchange Rate: the Role of Fundamentalists and Chartists, Open Economies Review, 4, 351-379.

[11] De Grauwe, P. and M. Grimaldi, 2004, Heterogeneity of Agents, Transaction Costs and the Exchange Rate, Journal of Economic Dynamics and Control, 29, 691-719.

[12] De Grauwe, P. and M. Grimaldi, 2005, The exchange rate in a behavioural finance framework, Princeton University Press, forthcoming.

[13] Diebold, F.X., Lee, J-H., Weinbach, G.C., 1994. Regime Switching with Time-Varying Transition Probabilities, in: Nonstationary Time Series Analysis and Cointegration, Hargreaves, C.P. (Ed)., Oxford University Press, Oxford, pp. 283-302.

[14] Dominguez, K.M., 1998, Central bank Intervention and Exchange Rate Volatility, Journal of International Money and Finance, 17, 161-190.

[15] Dominguez K.M., 2003, The Market Microstructure of Central Bank Intervention, Journal of International Economics, 59, 25-45.

[16] Fatum, R. and Hutchison, M. M. 2003, Is Sterelized Foreign Exchange Intervention Effective After All ? An Event Study Approach, The Economic Journal, 113, 390-411.

[17] Filardo, A. J., 1994. Business Cycles Phases and their Transitions, Journal of Business and Economics Statistics, 12, 299-308.

[18] Garcia, R., 1998. Asymptotic Null Distribution of the Likelihood Ratio Test in MarkovSwitching Models, International Economic Review, 39(3), 763-788.

[19] Hamilton, J.D.,1996. Specification Testing in Markov-switching time-series models, Journal of Econometrics, 70, 127-157.

[20] Humpage, O., 2003, Government Intervention in the Foreign Exchange Market, Federal Reserve Bank of Cleveland, Working Paper 03-15.

[21] Ito, T., 2003, Is Foreign Exchange Intervention Effective? The Japanese Experiences in the 1990's. In Paul Mizen (ed.), 
Monetary History, exchange Rates and Financial Markets, Essays in Honour of Charles Goodhart, volume 2,ChetelhamUK.;Edward Elgar Pub. London.

[22] Kim, C.J. , 1994. Dynamic linear Models with Markov Switching, Journal of Econometrics, $60,1-22$.

[23] Kim, C.J. and C.R. Nelson, 1999. State-Space Models with Regime Switching, MIT Press, Cambridge, Massachussets.

[24] Kearns, J. and R. Rigobon. 2004, Identifying the Efficacy of Central Bank Interventions: Evidence from Australia and Japan. Forthcoming in Journal of International Economics.

[25] Manzan, S. and F. Westerhoff, 2002, Heterogeneous Expectations, Exchange Rate Dynamics and Predictability, CeNDEF Working Paper 02/14.

[26] Morel, C. and J. Teïletche, 2004, Do Interventions in Foreign Exchange Markets Modify Investors' Expectations? The Experience of Japan Between 1992 and 2003, CDC Working Paper, September.

[27] Neely, C. J., 2001, The Practice of Central Bank Intervention: Looking under the Hood, Federal Reserve Bank of Saint-Louis Review, 83(3).

[28] Neely, C. J., 2004, The Case for Foreign Exchange Intervention: The Government as a Longterm Speculator, Federal Reserve Bank of Saint-Louis Working paper, November.

[29] Obstfeld, M., and Rogoff, K., 2000, "The Six Major Puzzles in International Macroeconomics: Is there a Common Cause?", NBER Working Paper no. 7777, July.

[30] Payne, R., and P. Vitale, 2003, A Transaction Level Study of the Effects of Central Bank Interventions on Exchange Rates, Journal of International Economics, 61, 331-352.

[31] Sarno, L., and M.P. Taylor, 2001, Official Intervention in the Foreign Exchange Market: is it Effective and, if so, How Does it Work? Journal of Economic Literature 39(3), 839-868.

[32] Vigfusson, R., 1996, Switching between Chartists and Fundamentalists: a Markov Regimeswitching Approach, Bank of Canada WP 96-1. 
[33] Williamson, J., and Miller, M., 1987, Targets and Indicators: A Blueprint for the International Coordination of Economic Policy, Institutre of International Economics, Washington, D.C. 


\section{CESifo Working Paper Series}

(for full list see www.cesifo-group.de)

1457 Margarita Katsimi and Thomas Moutos, Inequality and Relative Reliance on Tariffs: Theory and Evidence, April 2005

1458 Monika Bütler, Olivia Huguenin and Federica Teppa, Why Forcing People to Save for Retirement may Backfire, April 2005

1459 Jos Jansen, The Effects of Disclosure Regulation of an Innovative Firm, April 2005

1460 Helge Bennmarker, Kenneth Carling and Bertil Holmlund, Do Benefit Hikes Damage Job Finding? Evidence from Swedish Unemployment Insurance Reforms, May 2005

1461 Steffen Huck, Kai A. Konrad and Wieland Müller, Merger without Cost Advantages, May 2005

1462 Louis Eeckhoudt and Harris Schlesinger, Putting Risk in its Proper Place, May 2005

1463 Hui Huang, John Whalley and Shunming Zhang, Trade Liberalization in a Joint Spatial Inter-Temporal Trade Model, May 2005

1464 Mikael Priks, Optimal Rent Extraction in Pre-Industrial England and France - Default Risk and Monitoring Costs, May 2005

1465 François Ortalo-Magné and Sven Rady, Heterogeneity within Communities: A Stochastic Model with Tenure Choice, May 2005

1466 Jukka Pirttilä and Sanna Tenhunen, Pawns and Queens Revisited: Public Provision of Private Goods when Individuals make Mistakes, May 2005

1467 Ernst Fehr, Susanne Kremhelmer and Klaus M. Schmidt, Fairness and the Optimal Allocation of Ownership Rights, May 2005

1468 Bruno S. Frey, Knight Fever - Towards an Economics of Awards, May 2005

1469 Torberg Falch and Marte Rønning, The Influence of Student Achievement on Teacher Turnover, May 2005

1470 John Komlos and Peter Salamon, The Poverty of Growth with Interdependent Utility Functions, May 2005

1471 Hui Huang, Yi Wang, Yiming Wang, John Whalley and Shunming Zhang, A Trade Model with an Optimal Exchange Rate Motivated by Current Discussion of a Chinese Renminbi Float, May 2005

1472 Helge Holden, Lars Holden and Steinar Holden, Contract Adjustment under Uncertainty, May 2005 
1473 Kai A. Konrad, Silent Interests and All-Pay Auctions, May 2005

1474 Ingo Vogelsang, Electricity Transmission Pricing and Performance-Based Regulation, May 2005

1475 Spiros Bougheas and Raymond Riezman, Trade and the Distribution of Human Capital, June 2005

1476 Vesa Kanniainen, Seppo Kari and Jouko Ylä-Liedenpohja, The Start-Up and Growth Stages in Enterprise Formation: The "New View" of Dividend Taxation Reconsidered, June 2005

1477 M. Hashem Pesaran, L. Vanessa Smith and Ron P. Smith, What if the UK had Joined the Euro in 1999? An Empirical Evaluation Using a Global VAR, June 2005

1478 Chang Woon Nam and Doina Maria Radulescu, Effects of Corporate Tax Reforms on SMEs' Investment Decisions under the Particular Consideration of Inflation, June 2005

1479 Panos Hatzipanayotou, Sajal Lahiri and Michael S. Michael, Globalization, CrossBorder Pollution and Welfare, June 2005

1480 John Whalley, Pitfalls in the Use of Ad valorem Equivalent Representations of the Trade Impacts of Domestic Policies, June 2005

1481 Edward B. Barbier and Michael Rauscher, Trade and Development in a Labor Surplus Economy, June 2005

1482 Harrie A. A. Verbon and Cees A. Withagen, Tradable Emission Permits in a Federal System, June 2005

1483 Hendrik Hakenes and Andreas Irmen, On the Long-Run Evolution of Technological Knowledge, June 2005

1484 Nicolas Schmitt and Antoine Soubeyran, A Simple Model of Brain Circulation, June 2005

1485 Carsten Hefeker, Uncertainty, Wage Setting and Decision Making in a Monetary Union, June 2005

1486 Ondřej Schneider and Jan Zápal, Fiscal Policy in New EU Member States - Go East, Prudent Man!, June 2005

1487 Christian Schultz, Virtual Capacity and Competition, June 2005

1488 Yvan Lengwiler and Elmar Wolfstetter, Bid Rigging - An Analysis of Corruption in Auctions, June 2005

1489 Johannes Becker and Clemens Fuest, Does Germany Collect Revenue from Taxing Capital Income?, June 2005 
1490 Axel Dreher and Panu Poutvaara, Student Flows and Migration: An Empirical Analysis, June 2005

1491 Bernd Huber and Marco Runkel, Interregional Redistribution and Budget Institutions under Asymmetric Information, June 2005

1492 Guido Tabellini, Culture and Institutions: Economic Development in the Regions of Europe, July 2005

1493 Kurt R. Brekke and Michael Kuhn, Direct to Consumer Advertising in Pharmaceutical Markets, July 2005

1494 Martín Gonzalez-Eiras and Dirk Niepelt, Sustaining Social Security, July 2005

1495 Alfons J. Weichenrieder, (Why) Do we need Corporate Taxation?, July 2005

1496 Paolo M. Panteghini, S-Based Taxation under Default Risk, July 2005

1497 Panos Hatzipanayotou and Michael S. Michael, Migration, Tied Foreign Aid and the Welfare State, July 2005

1498 Agata Antkiewicz and John Whalley, BRICSAM and the Non-WTO, July 2005

1499 Petr Hedbávný, Ondřej Schneider and Jan Zápal, A Fiscal Rule that has Teeth: A Suggestion for a 'Fiscal Sustainability Council' underpinned by the Financial Markets, July 2005

1500 J. Atsu Amegashie and Marco Runkel, Sabotaging Potential Rivals, July 2005

1501 Heikki Oksanen, Actuarial Neutrality across Generations Applied to Public Pensions under Population Ageing: Effects on Government Finances and National Saving, July 2005

1502 Xenia Matschke, Costly Revenue-Raising and the Case for Favoring Import-Competing Industries, July 2005

1503 Horst Raff and Nicolas Schmitt, Why Parallel Trade may Raise Producers Profits, July 2005

1504 Alberto Bisin and Piero Gottardi, Efficient Competitive Equilibria with Adverse Selection, July 2005

1505 Peter A. Zadrozny, Necessary and Sufficient Restrictions for Existence of a Unique Fourth Moment of a Univariate GARCH(p,q) Process, July 2005

1506 Rainer Niemann and Corinna Treisch, Group Taxation, Asymmetric Taxation and Cross-Border Investment Incentives in Austria, July 2005

1507 Thomas Christiaans, Thomas Eichner and Ruediger Pethig, Optimal Pest Control in Agriculture, July 2005 
1508 Biswa N. Bhattacharyay and Prabir De, Promotion of Trade and Investments between China and India: The Case of Southwest China and East and Northeast India, July 2005

1509 Jean Hindriks and Ben Lockwood, Decentralization and Electoral Accountability: Incentives, Separation, and Voter Welfare, July 2005

1510 Michelle R. Garfinkel, Stergios Skaperdas and Constantinos Syropoulos, Globalization and Domestic Conflict, July 2005

1511 Jesús Crespo-Cuaresma, Balázs Égert and Ronald MacDonald, Non-Linear Exchange Rate Dynamics in Target Zones: A Bumpy Road towards a Honeymoon - Some Evidence from the ERM, ERM2 and Selected New EU Member States, July 2005

1512 David S. Evans and Michael Salinger, Curing Sinus Headaches and Tying Law: An Empirical Analysis of Bundling Decongestants and Pain Relievers, August 2005

1513 Christian Keuschnigg and Martin D. Dietz, A Growth Oriented Dual Income Tax, July 2005

1514 Fahad Khalil, David Martimort and Bruno Parigi, Monitoring a Common Agent: Implications for Financial Contracting, August 2005

1515 Volker Grossmann and Panu Poutvaara, Pareto-Improving Bequest Taxation, August 2005

1516 Lars P. Feld and Emmanuelle Reulier, Strategic Tax Competition in Switzerland: Evidence from a Panel of the Swiss Cantons, August 2005

1517 Kira Boerner and Silke Uebelmesser, Migration and the Welfare State: The Economic Power of the Non-Voter?, August 2005

1518 Gabriela Schütz, Heinrich W. Ursprung and Ludger Wößmann, Education Policy and Equality of Opportunity, August 2005

1519 David S. Evans and Michael A. Salinger, Curing Sinus Headaches and Tying Law: An Empirical Analysis of Bundling Decongestants and Pain Relievers, August 2005

1520 Michel Beine, Paul De Grauwe and Marianna Grimaldi, The Impact of FX Central Bank Intervention in a Noise Trading Framework, August 2005 